\title{
Learning objects, learning objectives and learning design
}

\author{
Fernando Alonso , Genoveva López, Daniel Manrique and José María Viñes \\ Facultad de Informática, Universidad Politécnica de Madrid, Madrid, Spain; Aulatika S.L., \\ Madrid, Spain
}

\begin{abstract}
Educational research and development into e-learning mainly focuses on the inclusion of new technological features without taking into account psycho-pedagogical concerns that are likely to improve a learner's cognitive process in this new educational category. This paper presents an instructional model that combines objectivist and constructivist leaming theories. The model is based on the concept of a leaming objective which is composed of a set of learning objects. A software tool, called the Instruction Aid System (IAS), has been developed to guide instructors through the development of learning objectives and the execution of the analysis and design phases of the proposed instructional model. Additionally, a blended approach to the learning process in Webbased distance education is also presented. This approach combines various event-based activities: self-paced learning, live e-learning and the use of face-to-face contact in classrooms.
\end{abstract}

Keywords: learning objects; learning objectives; instructional model; blended learning

\section{Introduction}

A genuine education system should not focus on the transmission of knowledge from teachers to pupils (Govindasamy, 2002), it should be concerned with the fundamental aspect of education, that is, learning. Learning is the acquisition of new mental schemata, knowledge, abilities, skills, etc., that can be used to solve problems potentially more successfully.

Initially, e-learning systems, technologically supported by learning objects, did not provide any means to support content production processes, e-content management or even maintenance (Ismael, 2002). The concept of a learning object usually refers to a smallsized, reusable instructional component, designed for distribution over the Intemet, for use in different learning management systems (LMS) and for access by many users (Anido \& Santos, 2001).

Later, e-learning systems addressed the issue of educational e-content reusability, by means of which the same educational content could be used across different courses that are accessible over the Internet (Muzio, Heins, \& Mundell, 2002). Thanks to this potential, an e-learning management system can select different learning objects for different learners (Sampson, 2002). Nowadays, these e-learning systems are able to generate adaptive e-learning content on demand, that is, produce a 'made-to-measure' course depending on what a learner already knows (Alonso, López, Manrique, \& Fernández, 2004; Atif, Benlamri, \& Berri, 2003).

All this technology (developed around the e-learning paradigm) is beneficial for 'improving the quality of learning', but is useless if it is not based on psycho-pedagogical 
prescriptions (Alonso, López, Manrique, \& Viñes, 2005). There is now a serious dysfunction between the profusion of technological features that are put forward and the shortage of pedagogical manners and teaching principles for e-learning (Tallent-Runnels et al., 2005). Pedagogical principles are theories that govern good educational practice, and, as far as e-learning is concemed, good educational or instructional practice is implemented by the instructional design. Instructional design has evolved on a par with the development of the three basic learning theories: behaviourism, cognitivism, and constructivism.

The theory of behaviourism concentrates on the study of overt behaviours that can be observed and measured. It views the mind as a 'black box' in the sense that responses to a stimulus can be observed quantitatively, totally ignoring the possibility of thought processes occurring in the mind (Good \& Brophy, 1990). This is precisely one of the limitations of behaviourism: it is unable to understand learning.

The cognitive theory views learning as involving the acquisition or reorganisation of the cognitive structures used by human beings to process and store information. Mental processes transform the information received into knowledge and skills within human memory. The influence of cognitive science on instructional design is evidenced by the use of advanced organisers, metaphors, chunking into meaningful parts, and the careful organisation of instructional materials from simple to complex (Anderson, 1996).

Constructivism builds upon behaviourism and cognitivism in the sense that it accepts multiple perspectives and maintains that learning is a personal interpretation of the world. Constructivist theory sustains that learner's construct or at least interpret their own reality based upon their perception of experiences. Therefore, an individual's knowledge is a function of his or her prior experiences, mental structures, and beliefs that are used to interpret objects and events (Jonassen, 1991).

This paper presents an e-learning instructional model. This model is supported by the eclectic combination of the above learning theories and is based on the concept of the learning objective, composed of learning objects. The proposed model includes prescriptions and methods borrowed from different fields of knowledge. For the design and implementation of the educational content, we have used principles based on the content performance matrix (Merrill, 1997) and multimedia principles derived from the latest research on information processing psychology within the field of cognitive psychology (Clark, 2003). The educational content (facts, concepts, procedures and principles) are structured on the basis of the concept of a learning objective. The learning objective is defined as a set of learning objects that can be evaluated according to performance goals to develop coherent information structures that help to build knowledge schemata in a learner's mind (Donovan, Bransford, \& Pellegrino, 1999). A collaborative environment is developed, including activities designed to create a social environment that acts as a scaffold for collaborative learning and dialectical constructivism (Palloff \& Pratt, 1999, 2003). The proposed model maps constructivist principles to the instructional design by means of a more pragmatic approach that focuses on the principles of moderate constructivism (Karagiorgi \& Symeou, 2005), making use of emergent technology tools. An Instruction Aid System (IAS) has been implemented as a tool for guiding instructors through the construction of the instructional model.

Orthogonal to this instructional view is the learner's perspective. By learner's perspective we mean how the learning should be staged for the learner to optimally acquire the knowledge. A number of specialists in the subject advocate a blended learning solution (Garrison \& Kanuka, 2004; Thorne, 2003), a concept used to describe learning that mixes different activities. We propose a blended approach to the leaming process that fits the psycho-pedagogical prescriptions defined in our instructional method for e-learning. This blended learning mixes three ingredients: self-paced learning that provides the right skills 
at the right time (Carman, 2002), live e-learning in a virtual classroom where learners can collaborate (Stahl, 2005) and traditional classroom training, which is necessary to learn management, leadership and collaborative skills (Michell, 2001).

\section{Learning objects and learning objectives}

A learning object deals with a very specific item of knowledge: educational content, a 'good problem' to be solved through group work or evaluation exercises, etc. Learning objects should be self-contained and can be combined to support individual instructional objectives for use in different contexts.

Learning objects have several names in the learning field. Nevertheless, the sharable content object (SCO), coined by the Sharable Content Object Reference Model (SCORM) from the concept of learning object given by the IMS Global Learning Consortium (2004), is the most commonly accepted term with regard to leaming and reuse elements. The structure of a SCO includes other content elements, called assets. Assets are electronic representations of media, text, images, sound, web pages, assessment objects or other pieces of data that can be delivered to a web client. So, a SCO represents a collection of one or more assets that, together, define a single, self-contained learning item. Learning objects are designed and developed by the subject content expert using any SCORM-compatible authoring tool, and are stored in a leaming objects repository for reuse in different educational contexts.

By way of an example, suppose a group of learners are to be trained in Java programming. Figure 1 illustrates the appearance (interface) of a SCO called Class and Object, which describes these concepts, their operation and programming. It shows that Class and Object is composed of two assets: a GIF file containing an image that describes these concepts and the differences between them, and a HTML file containing the text and format of the explanation, hyperlinks to references with additional content and buttons to navigate to other interrelated SCOs.

A good learning object should be founded on strong instructional design, such as Merrill's Component Display Theory (Merrill, 1994). Its stated assumption is that, for all educational contents, there are corresponding instructional treatments that should be used. Effective treatments may include the appropriate use of examples, counter-examples, instructional animations, try-it interactions, drill and practice, flash card exercises and hands-on labs.

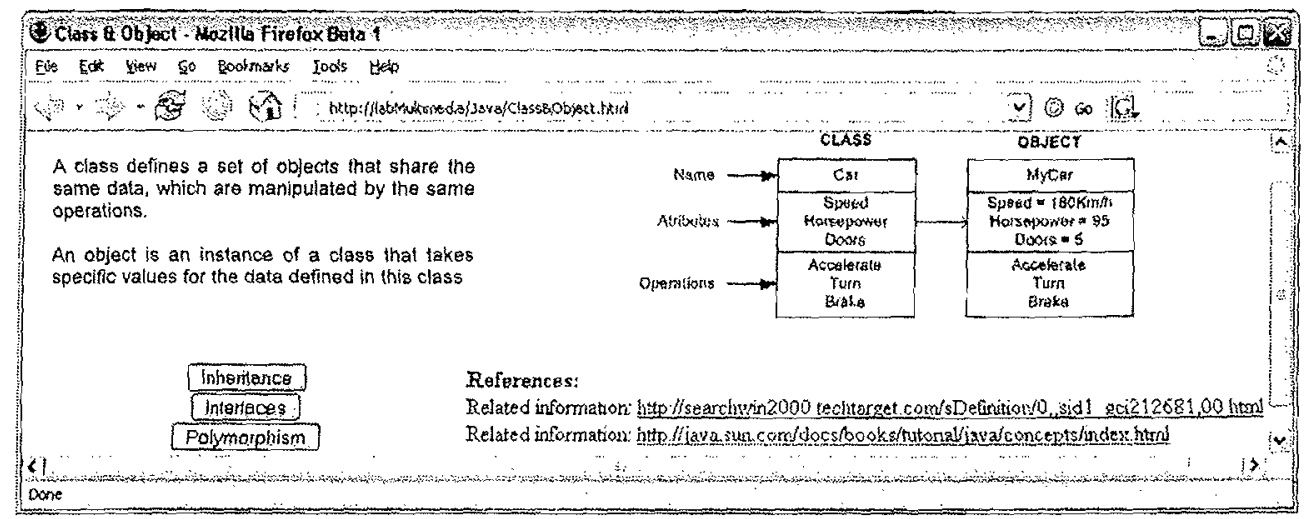

Figure 1. Class and Object interface on a learner's screen. 
The use of multimedia is a powerful tool for promoting knowledge transfer in learning object design. Three principles taken from Clark (Clark \& Mayer, 2002) deserve special attention: (1) the multimedia principle states that adding graphics to text can improve learning; (2) the contiguity principle indicates that placing text near graphics improves learning, and (3) the modality principle establishes that explaining graphics with audio improves learning in situations where overload is likely. Not all designers are of this opinion, however. We take up Schonotz's findings and try to prevent taskinappropriate graphics from interfering with mental model construction (Schonotz \& Bannert, 2003).

A learning objective is the specific knowledge that a learner has to acquire about a concept or skill and the tasks to be performed. A learning objective includes several learning objects. Each learning objective will be defined by a set of interrelated SCOs that each deal with a very specific item of knowledge. These relations can be represented by means of an AND/OR graph, where the nodes represent SCOs and the directed lines indicate learning sequences. AND learning occurs when two or more directed lines have the same target node: this indicates that all the source SCOs need to have been completed before starting on the target SCO. OR learning occurs when two or more lines are directed at a node: the target SCO can start to be learned when either of the source SCOs have been completed. An arrow without a source node indicates that the learning objective can start to be learned as of the $\mathrm{SCO}$ to which it points.

A learning objective should be composed of SCOs that contain: educational contents, a 'good problem' for group problem solving that covers the concepts described in the educational contents, and evaluation exercises to evaluate the knowledge acquired by the learner. The required knowledge state for a learning objective is considered to have been attained when its evaluation exercises have been passed, for which purpose the 'good problem' necessarily has to be solved. A 'good problem' should prompt the exploration and reflection required to build knowledge. According to Brooks and Brooks (1993), a 'good problem' is one that requires students to make and test a prediction, can be solved with inexpensive equipment, is realistically complex, benefits from group effort and is seen as relevant and interesting by students.

For the Java programming example, we defined a learning objective, called ObjectOriented Fundaments (OOF), with six SCOs: Class and Object, Interfaces, Inheritance and Polymorphism as educational contents, a Good Problem and, finally, a SCO with evaluation exercises. The 'good problem' used for this learning objective involves modelling a company's organisational chart based on the employed concept, where the different job types and functions have to be represented according to the business area to which they belong and their position in the hierarchy.

Figure 2 shows the OOF learning objective designed using the IAS tool, illustrating the interrelations between its SCOs mapped by the AND/OR graph. Looking at the graph, we find that learners can start with Class and Object or directly get on with the good problem, which is the target of an OR learning sequence. If the learner opts for the first alternative, there are three available leaming sequences. This indicates that, after having learned this $\mathrm{SCO}$, the learner can continue the learning process by choosing between the SCOs on Inheritance or Interfaces or tackle the good problem. There is an AND learning sequence from Inheritance and Interfaces to Polymorphism: the first two have to have been completed before starting on the last.

From the instructional viewpoint, learning objectives include features inspired by different learning theories. On the one hand, they cover the key characteristics of constructivism: the requirement that any learning objective should contain a 'good problem', a meaningful 


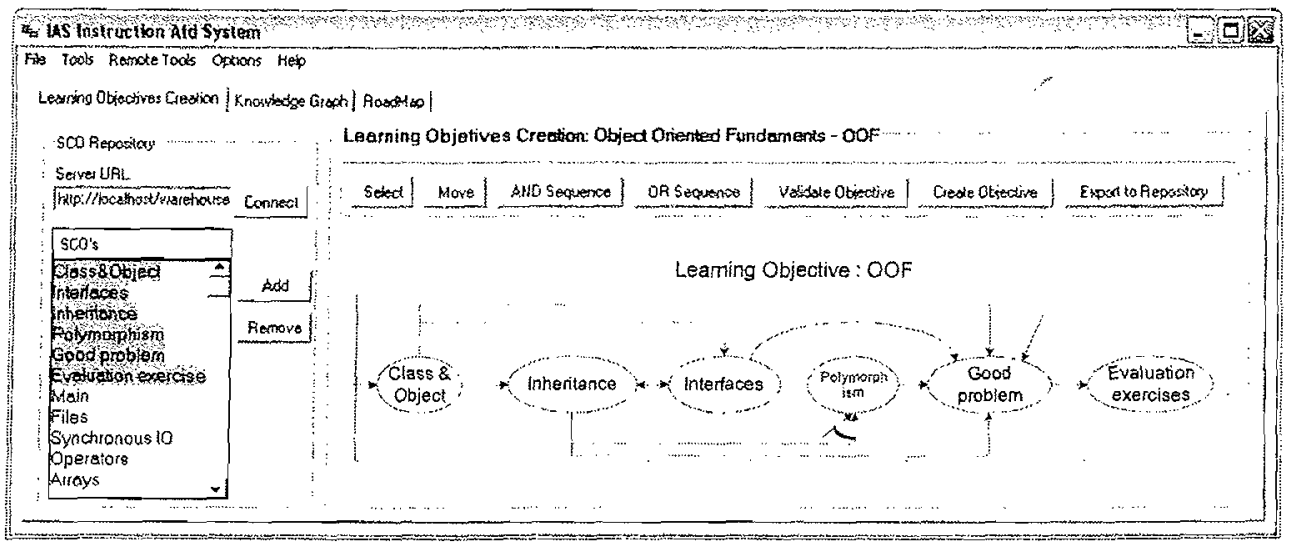

Figure 2. IAS assisting the design of the OOF learning objective.

and realistic problem, and that problem solving should be collaborative so that learners learn through interaction with others (Tam, 2000).

On the other hand, the learning objectives include features proper to objectivism (behaviourism and cognitivism). The very term learning objective indicates that teaching is objective driven and, also, that these objectives can be evaluated, for which purpose evaluation exercises are included. These last two features overcome the most widely criticised drawbacks of using a purely constructivist philosophy, namely the absence of specific learning objectives and outcomes, leading to an inefficient and ineffective leaming process (Cey, 2001), and the notion of there not being 'right' or 'wrong' answers, which strikes fear into the heart of an instructor (Corich, 2004).

\section{The instructional model}

During learning learners acquire three levels of knowledge: the syntactic level, the semantic level and the pragmatic level, which Bloom defined within his taxonomy of educational objectives (knowledge, comprehension, application, analysis, synthesis, and evaluation) (Bloom, 1956). At the last level, learners are able to apply the knowledge acquired to solve particular problems. They can also evaluate the methods, processes, and tools to be used, which they can judge both qualitatively and quantitatively.

Schulman (2002) identifies a six-stage learning process: engagement and motivation, knowledge and understanding, performance and action, reflection and critique, judgement and design, and commitment and identity. Learning begins with student engagement, which in turn leads to knowledge and understanding. Once a learner understands, he or she becomes capable of performance or action. Critical reflection on one's practice and understanding leads to higher-order thinking in the form of an ability to exercise judgement in the face of uncertainty and to create designs in the presence of constraints and unpredictability. Finally, by exercising judgement, a learner develops commitment. In commitment, he or she becomes capable of professing his or her understandings and his or her values, internalising those attributes and making them integral to his or her identity. These commitments, in turn, make new engagements possible and even necessary.

The proposed e-learning instructional model is based on the fact that training should enable learners to apply the concepts leamed at their workplace and evaluate the results. In 
other words, it should provide the pragmatic level and the practical tools for the leamers to be able to put into practice what they have learned. This instructional model applies the systematic development of instruction and learning and is composed of five phases: analysis, design, implementation, execution and evaluation.

\section{Analysis}

This phase defines what to teach, and therefore analyses the learner and the educational contents to be taught. Its purpose is to detect a learner's learning characteristics and needs, and to ascertain what sort of environment the learning is to take place in and what resources are available. It outputs the learning objectives with their educational contents and their interrelations. These define the knowledge and skills to be leamed and the tasks to be performed to acquire the goal knowledge state.

The learning objectives and their relationships are represented by means of a knowledge graph. This is an AND/OR graph. In this case, however, the arrows represent learning objective learning sequences, and the nodes are the learning objectives. The proposed model is an objective-driven instructional model with constructivist learning, giving the learner the chance to choose, subject to some constraints imposed by the content structure, the next learning objective, following the overarching idea in Ausubel's theory (Ausubel, Novak, \& Hanesian, 1978).

Figure 3 shows the knowledge graph for the Java Programming example that the instructor has designed from our learning objectives repository using the IAS tool. It is composed of nine learning objectives: Basic Syntax, Methods, Sentences, OOF, Packages, Exceptions, Threads, Input/Output (I/O) and Graphical User Interface (GUI). A characteristic of this knowledge graph is that it has a great many $O R$ learning sequences, which gives the learner greater freedom. For example, once the Basic Syntax leaming objective has been achieved, the learner has the option of starting either Sentences or Methods, whereas there is an AND learning sequence from Sentences and Methods to attain the OOF learning objective.

\section{Design}

The design defines how to teach. 'Good problems' are designed for each learning objective as a condition for attaining the target knowledge states. These are problems that have to be

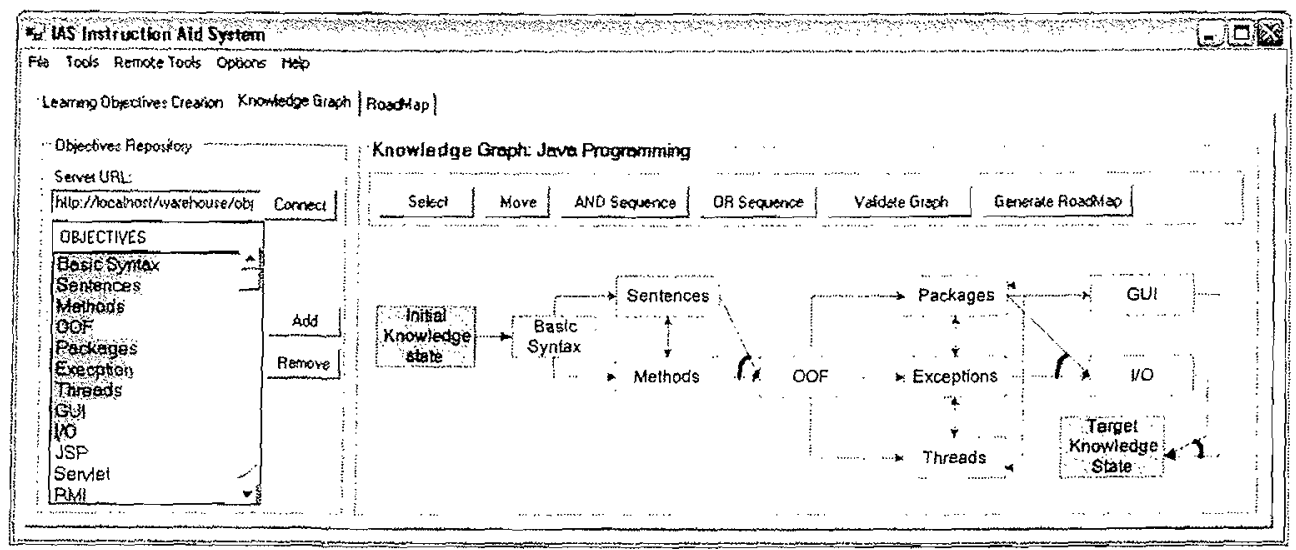

Figure 3. IAS assisting the creation of the knowledge graph for the Java Programming example. 
solved through group work, setting up a realistically complex collaborative learning environment. The aim is for learners to learn authentically by developing associations between concepts and reflective meta-cognitive processes that are meaningful for working out effective ways to deal with problem situations. Also there should be different ways of solving the problems to give learners multiple and alternative perspectives. Evaluation exercises must also be set to assess what knowledge has been acquired. This phase establishes the tools, techniques and environments that are to be used for teaching: hypermedia, multimedia and the Internet to improve data gathering, collaboration and offer multiple representations of reality.

Each learner's learning process is also specified together with the educational activities that will take place within this process, standards to be used, execution criteria and achievement expected of the learner. This instructional model involves a blended learning approach to the learning process that includes three learning types: self-paced learning, live e-learning and the use of face-to-face contact in classrooms.

\section{Self-paced learning}

Self-paced learning is an interactive mode of learning over the Internet that each learner does on his or her own, at his or her pace and in his or her time. It is asynchronous learning that adds significant value to the blended learning equation. The self-paced learning process is designed by means of a road map. The road map is a graph that represents and interrelates the learning objectives and their learning objects leading to a knowledge state. Therefore, the road map represents the set of all possible paths that go from the initial to the goal knowledge state. The instructor uses the IAS to define and incorporate the global problem and the evaluation exercises for each learning objective, and the system automatically produces the road map from the knowledge graph. Due to the complexity of the whole diagram, Figure 4 shows the road map generated by IAS for the Java Programming example only, covering the following four learning objectives: Basic Syntax, Sentences, Methods and OOF. All these learning objectives are included in the knowledge graph shown in Figure 3.

\section{Live e-learning}

Live e-learning is a synchronous process. It is a mode of collaborative learning that can be implemented by means of video-conferences, threaded discussions, online chats or virtual

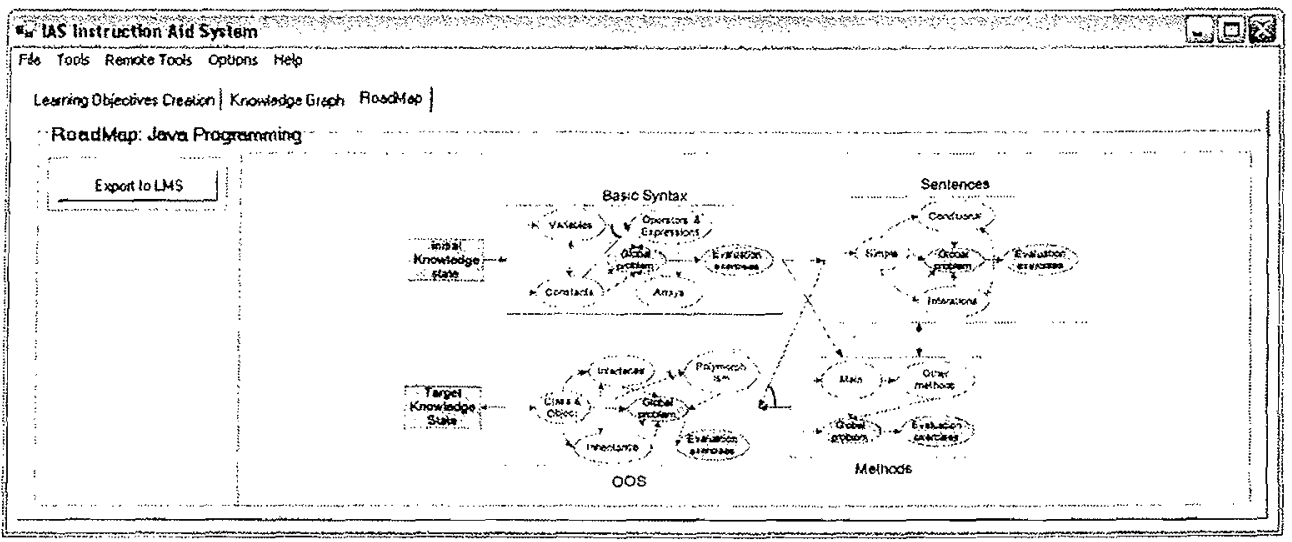

Figure 4. Road map for part of the Java Programming self-paced learning process. 
classrooms at a scheduled time. Leamers collaborate, share information, and ask questions of one another and of the instructor in real time. Live e-learning is good for sharing information. To create an engaging, effective live e-leaming experience, the four fundamental elements in Keller's ARCS Model of Motivation (Keller, 1987) have been taken into account: attention, relevance, confidence, and satisfaction.

The power of combining live e-leaming and self-paced learning is augmented drastically when there is meaningful collaboration. Collaborative learning affords students enormous advantages that they cannot get from more traditional instruction because a group can accomplish meaningful learning and solve problems better than any individual can alone (Brown, 1998; Dillenbourg, Baker, Blaye, \& O'Malley, 1995). Bruffee advocates that students learn best in an environment where a sense of community exists (Bruffee, 1987, 1995). Pallof and Pratt (1999) also clearly state the importance of collaboration.

\section{Face-to-face contact}

The face-to-face or traditional classroom is the third ingredient of blended leaming. Classroom training is, despite its defects, still unbeatable for the amount of face-to-face interaction with both the instructor and classmates (Pazos, Azpiazu, Silva, \& RodriguezPatón, 2002).

\section{Implementation}

This phase involves building the road map into a learning management system (LMS) platform at design time. Figure 5 shows the implementation of the Java Programming example in a SCORM-compatible authoring tool. The left-hand side of this screenshot shows the

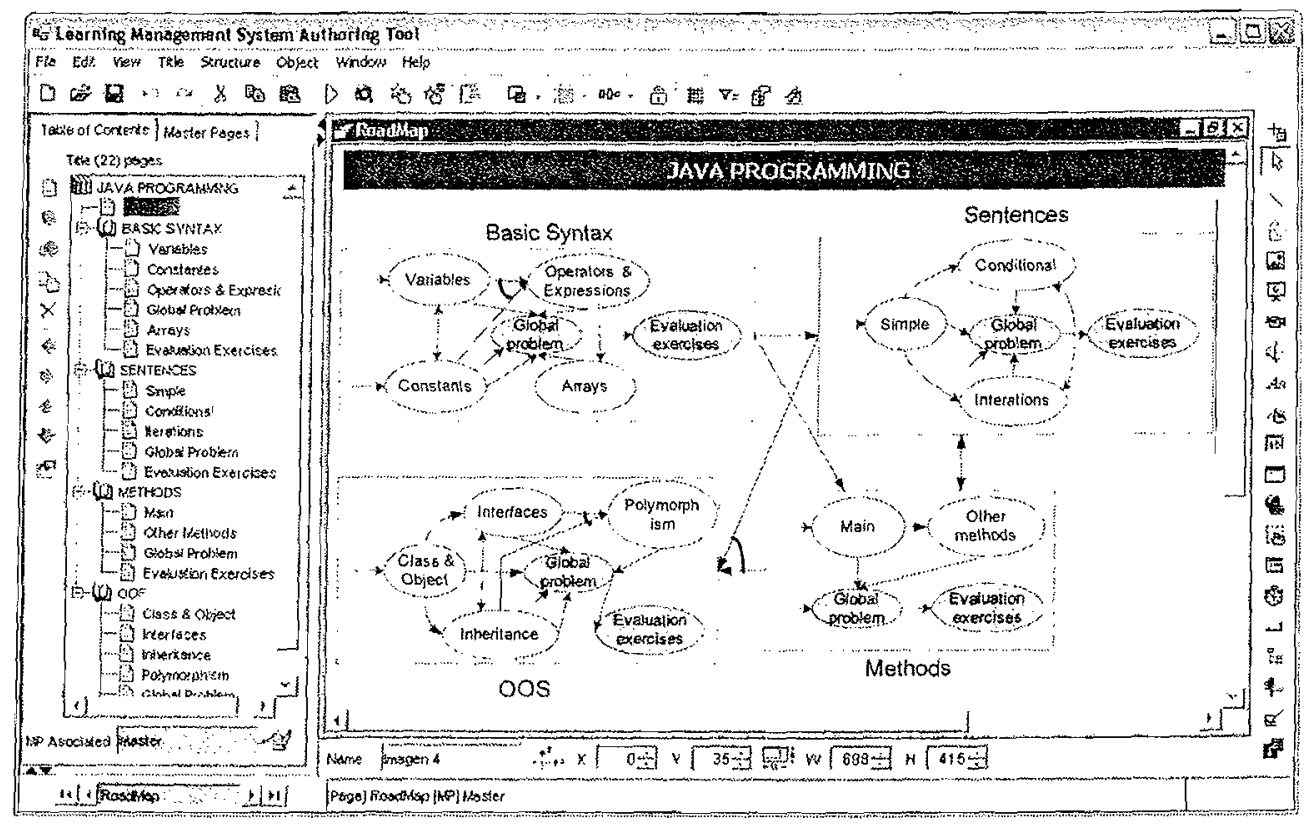

Figure 5. The Java Programming example has been uploaded to an authoring tool. 
content tree and the right-hand side explains to the learner what the actual self-paced learning process (through the road map illustrated in Figure 4) will be like. Hyperlinks have been added to highlight the learning objects at which the learner can start: Variables and Constants.

\section{Execution}

This phase involves the learner executing the learning process. Execution provides information on the problems encountered and the knowledge acquired.

We have been training Spanish central and local administration computing specialists for over 11 years through the Master in Information and Communications Technologies Management (INAP, 2005). We first applied classroom learning. Then we applied distance learning by virtualising the educational content and using video-conferencing to simulate face-to-face instruction. Three years ago we incorporated the instructional model described in this paper, applying live e-learning and self-paced learning. From this experience and the results shown in the evaluation phase, we can say that a blended learning process is well adapted to an eight-week course of 80 learning hours executed as follows:

(1) The course started with a one-day face-to-face session where the learners had the chance to meet each other and the e-learning tutor. The tutor presented the learning objectives, discussed the most significant knowledge and tasks to be learned, and described the interactions that were to be used (email, chat, and video-conferences).

(2) One-hour interactions between learners and between learners and the instructor were held every two days via chat so as to consolidate and acquire knowledge. The chat was held informally, and its development was not structured.

(3) Computerised video-conferences were broadcast in the second, fourth and sixth weeks. To assure that they were efficient, the subjects to be dealt with were planned and structured beforehand.

(4) There was permanent email support, which was always answered within 24 hours.

(5) There was telephone support for one hour a day. Learners were encouraged to outline the subject via email previously.

(6) Assessment: a face-to-face assessment was held immediately after the course finished. The content of the examination included questions related to real cases, to which, the concepts learned throughout the course were applied. The examination could last anything from 45 minutes to two hours. Evaluation of learners took into account the scores achieved in this test, the solution of exercises set throughout the course and the learner's participation in live e-learning sessions.

\section{Evaluation}

In order to determine successes and ascertain the learning product quality, information output during execution is gathered and the results are analysed on the basis of the learning objects and objectives. For the educational content learning objects and the good problems, the total time each learner spends on learning with an object is stored, and the interaction between learners, between learners and the tutor, and the number of questions formulated by the learner are recorded. Finally, the marks that learners obtain in the evaluation exercises and the total time they spend on learning an objective are stored.

The content expert can analyse this information to find out whether an educational content learning object should be revised, for example, if the mean time spent studying the 
learning object is significantly higher than originally estimated by the ccntent expert at design time. Similarly, it provides the instructor with statistical data about the execution of the learning objectives from which he or she will be able to ascertain whether any have been poorly designed. From this information, the instructor can draw conclusions such as: abnormally low marks or too much interaction to solve a global problem.

The results achieved by learners in the final assessment that is held at the end of the course have been evaluated. This evaluation analysed all three different teaching approaches for the Java Programming course: face-to-face classroom learning, distance learning virtualising all the teaching material used in the classroom, and distance learning with the proposed instructional model implemented in the IAS tool and a blended learning process. The number of students involved in this study was 79, 78 and 78 , respectively. The mean grades (out of a maximum score of 10 ) in the final examination were 6.9 (SD = 1.98), 5.65 $(\mathrm{SD}=2.39)$ and $6.6(\mathrm{SD}=2.01)$, respectively. Therefore, the results of teaching the Java Programming course in a face-to-face classroom or by distance learning supported by the IAS and the blended learning process are similar, with the benefit that the distance learning option cuts costs considerably. These results also show how learning suffers if translated directly from traditional to distance learning format: a one-point drop out of 10 in students' average grades. The findings for other Information and Communication Technology courses now taught for Public Administration were similar.

\section{Conclusion}

This paper presents an instructional model that combines objectivist and constructivist learning theories. From objectivism, we have borrowed the decomposition of the educational content into learning objectives. These objectives represent a knowledge state that can be evaluated through evaluation exercises. So, the instructional model proposed is objective driven.

From a constructivist point of view, the instructional model includes so-called 'good problems', which simulate and recreate real-life complexities and occurrences, can be solved in different ways and should be solved through group work to create a collaborative learning environment and give learners access to multiple perspectives. These characteristics furnish the model with the four most important constructivist strategies, which are, respectively, authentic learning, active learning, collaborative learning and multiple perspectives.

The application of constructivism to instructional design has some benefits, such as more meaningful learning outcomes, more independent problem-solving skills, and more flexibility in both design and instruction activities. However, the translation of pure constructivism into practice has some drawbacks: (1) the evident autonomy of learners in knowledge construction makes it very difficult to predict how learners will learn or how to plan learning activities; (2) it is extremely difficult to set standards to assess the meaningfulness of the learning, and (3) learners might construct wrong knowledge bccause they have almost unlimited freedom of choice to select what to and how to study from among available resources. Therefore, we can conclude that the proposed instructional model translates pure constructivism into a more pragmatic approach that focuses on the principles of moderate constructivism in an attempt to make the most of the benefits of this theory and avoid its drawbacks. The IAS tool is a valuable aid for developing learning objectives and analysing and designing instructional phases by graphically expressing the relationships between learning objects and objectives and detecting inconsistencies

The instructional model also includes a blended learning approach to the learning process, which, according to several authors (Alonso et al., 2004; Garrison \& Kanuka, 2004; 
Clark, R. (2003). Building expertise. Cognitive methods for training and performance improvement. Washington, DC: Book of International Society for Performance Improvement.

Clark, R., \& Mayer, R. (2002). E-Learning and the science of instruction. Proven guidelines for consumers and designers of multimedia learning. San Francisco: Jossey-Bass/Pfeiffer.

Corich, S. (2004). Instructional design in the real world: A view from the trenches [Book review]. Educational Technology and Society, 1, 128-129.

Dillenbourg, P., Baker, M., Blaye, A., \& O'Malley, C. (1995). The evolution of research on collaborative learning. In E. Spada \& P. Reiman (Eds.), Learning in humans and machine: Towards an interdisciplinary learning science (pp. 189-211). Oxford: Elsevier.

Donovan, M.S., Bransford, J.D., \& Pellegrino, J.W. (Eds.). (1999). How people learn: Bridging research and practice. Washington, DC: National Research Council Committee on Learning Research and Educational Practice.

Garrison, D.R., \& Kanuka, H. (2004). Blended learning: Uncovering its transformative potential in higher education. Internet and Higher Education, 7, 95-105.

Good, T.L., \& Brophy, J.E. (1990). Educational psychology: A realistic approach (4th ed.). White Plains, NY: Longman.

Govindasamy, T. (2002), Successful implementation of e-leaming pedagogical considerations. Internet and Higher Education, 4, 287-299.

IMS Global Learning Consortium, Inc. (2004). Content packaging specification, version 1.1.2. Retrieved Februaty 15, 2004, from http://www.imsglobal.org/

INAP. (2005). Master in Information and Communications Technologies. Retrieved November 24 2005, from National Public Administration Institute web site: http://www.teleinap.com

Ismael, J, (2002). The design of an e-learning system. Beyond the hype. Intemet and Higher Education. 4, 329-336

Jonassen, D.H. (1991). Objectivism versus constructivism: Do we need a new philosophical paradigm? Educational Technology and Research and Development, 39, 5-14

Karagiorgi, Y., \& Symeou, L. (2005). Translating constructivism into instructional design: Potential and limitations. Educational Technology and Society, 8(1), 17-27.

Keller, J.M. (1987). Strategies for stimulating the motivation to learn. Performance and Instruction, $8,1-7$.

Merrill, M.D. (1994). Instructional design theory. Englewood Cliffs, NJ; Educational Technology Publications.

Merrill, M.D. (1997, November-December). Instructional strategies that teach. CBT Solutions, pp. $1-11$.

Michell, L. (2001, April). E-Learning methods offer a personalized approach. InfoWorld, pp. 174-185.

Muzio, J.A., Heins, T., \& Mundell, R. (2002). Experiences with reusable e-learning objects. Internet and Higher Education, 5, 21-34.

Palloff, R., \& Pratt, K. (1999). Building learning communities in cyberspace: Effective strategies for online classroom. San Francisco: Jossey-Bass.

Palloff, R., \& Pratt, K. (2003). The virtual student: A profile and guide to working with online learn. ers. San Francisco: Jossey-Bass.

Pazos, J., Azpiazu, J., Silva, A., \& Rodríguez-Patón, A. (2002). A virtual classroom based on academic memories. In Proceedings of Information Society and Education: Monitoring a Revolution. Badajoz, Spain: Government of Extremadura (pp. 87-92).

Sampson, D. (2002). An architecture for web-based e-learning promoting re-usable adaptive educational e-content. Educational Technology and Society Journal, 5(4), 27-37.

Schonotz, W., \& Bannert, M. (2003). Construction and interference in learning from multiple representations. Learning and Instruction, $13(2), 141-156$.

Schulman, L.S. (2002). Making differences: A table of learning. Change, 34, 36-44.

Stahl, G. (2005). Group cognition in computer-assisted collaborative learning. Journal of Computer Assisted Learning, 2, 79-90.

Tallent-Runnels, M.K., Lan, W.Y., Fryer, W., Thomas, J.A., Cooper, S., \& Wang, K. (2005). The relationship between problems with technology and graduate students' evaluations of online teaching. Internet and Higher Education, 8, 167-174

Tam, M. (2000). Constructivism, instructional design and technology: Implications for transforming distance leaming. Educational Technology and Society, 2, 124-138.

Thorne, K. (2003). Blended learning: How to integrate online and traditional learning. London: VA Kogan. 
Thorne, 2003), is the most efficient teaching model. This approach combines self-paced learning, live e-learning and face-to-face classroom learning. Our experience over several years training information technology specialists and the results reported in this paper backed this hypothesis and led us to present a specific implementation.

\section{Notes on contributors}

Fernando Alonso is a full professor at the Madrid Technical University's School of Computing. His activities focus on classroom undergraduate and postgraduate Computing Engineering education and on blended learning in Masters in Information and Communications Technology. He is Research Director at the Centre of Computing and Communications Technology Transfer. He has numerous publications in international journals.

Genoveva López is a professor at the Madrid Technical University's School of Computing. Her activities focus on classroom undergraduate and postgraduate Computing Engineering education and on blended learning in Masters in Information and Communications Technology. She directs all the elearning activities of the Centre of Computing and Communications Technology Transfer. She has numerous publications in international journals.

Daniel Manrique is a professor at the Madrid Technical University's School of Computing. His activities focus on classroom undergraduate and postgraduate Computing Engineering education and on blended learning in Masters in Information and Communications Technology. He directs e-learning work groups at the Centre of Computing and Communications Technology Transfer. He has numerous publications in international journals.

José M. Viñes is an aeronautics engineet and holds a degree in psychology. He is a psychopedagogical advisor on the design and development of e-learning contents. He specialises in applying psychocognitive principles to the mental processes of learning.

\section{References}

Alonso, F., López, G., Manrique, D., \& Fernández, F.J. (2004). Constructing adapted E-learning courses on demand. Paper presented at the IADIS International Conference E-Society, Avila, Spain.

Alonso, F., López, G., Manrique, D., \& Viñes, J.M. (2005). An instructional model for web-based elearning education with a blended learning process approach. British Journal of Educational Technology, 1, 217-235.

Anderson, N.H. (1996). A functional theory of cognition. Mahwah, NJ: Lawrence Erlbaum Associates.

Anido, L., \& Santos, J. (2001). A component model for standardized web-based education. Paper presented at the 10th International World Wide Web Conference, Hong Kong.

Atif, Y., Benlamri, R., \& Berri, J. (2003). Learning objects based framework for self-adaptive learning. Education and Information Technologies, 8, 345-368.

Ausubel, D., Novak, J., \& Hanesian, H. (1978). Educational psychology: A cognitive view (2nd ed.). New York: Holt, Rinehart and Winston.

Bloom, B.S. (1956). Taxonomy of educational objectives. Book 1, Cognitive domain. New York: Longman.

Brooks, J.G., \& Brooks, M.G. (1993). In search of understanding: The case for constructivist classrooms. Alexandria, VA: American Society for Curriculum Development.

Brown, B.M. (1998). Digital classrooms: Some myths about developing new educational programs using the internet. T.H.E. Journal. Retrieved September 3, 2005, from http://www.thejournal. $\mathrm{com} / \mathrm{magazine} / 98 / \mathrm{dec} / \mathrm{feat} 04 . \mathrm{html}$

Bruffee, K.A. (1987). The art of collaborative learning: Making the most of knowledgeable peers. Change, 19(2), 42-47.

Bruffee, K.A. (1995). Sharing our toys: Cooperative learning versus collaborative learning. Change, $27(1), 12-18$.

Carman, J.M. (2002). Blended learning design: Five key ingredients. Retrieved October 24, 2004, from http://www.knowledgenet.com/pdf/Blended\%20 Learning\%20Design_1028.PDF

Cey, T. (2001). Moving towards constructivist classrooms. Saskatoon, Canada: University of Saskatchewan Saskatoon. 
Clark, R. (2003). Building expertise. Cognitive methods for training and performance improvement. Washington, DC: Book of International Society for Performance Improvement.

Clark, R., \& Mayer, R. (2002). E-Learning and the science of instruction. Proven guidelines for consumers and designers of multimedia learning. San Francisco: Jossey-Bass/Pfeiffer.

Corich, S. (2004). Instructional design in the real world: A view from the trenches [Book review]. Educational Technology and Society, 1, 128-129.

Dillenbourg, P., Baker, M., Blaye, A., \& O'Malley, C. (1995). The evolution of research on collaborative learning. In E. Spada \& P. Reiman (Eds.), Learning in humans and machine: Towards an interdisciplinary learning science (pp. 189-211). Oxford: Elsevier.

Donovan, M.S., Bransford, J.D., \& Pellegrino, J.W. (Eds.). (1999). How people learn: Bridging research and practice. Washington, DC: National Research Council Committee on Learning Research and Educational Practice.

Garrison, D.R., \& Kanuka, H. (2004). Blended learning: Uncovering its transformative potential in higher education. Internet and Higher Education, 7, 95-105.

Good, T.L., \& Brophy, J.E. (1990). Educational psychology: A realistic approach (4th ed.). White Plains, NY: Longman.

Govindasamy, T. (2002). Successful implementation of e-learning pedagogical considerations. Internet and Higher Education, 4, 287-299.

IMS Global Learning Consortium, Inc. (2004). Content packaging specification, version 1.1.2. Retrieved February 15, 2004, from http://www.imsglobal.org/

INAP. (2005). Master in Information and Communications Technologies. Retrieved November 24, 2005, from National Public Administration Institute web site: http://www.teleinap.com

Ismael, J. (2002). The design of an e-learning system. Beyond the hype. Internet and Higher Education, 4, 329-336.

Jonassen, D.H. (1991). Objectivism versus constructivism: Do we need a new philosophical paradigm? Educational Technology and Research and Development, 39, 5-14.

Karagiorgi, Y., \& Symeou, L. (2005). Translating constructivism into instructional design: Potential and limitations. Educational Technology and'Society, 8(1), 17-27.

Keller, J.M. (1987). Strategies for stimulating the motivation to learn. Performance and Instruction, $8,1-7$.

Merrill, M.D. (1994). Instructional design theory. Englewood Cliffs, NJ: Educational Technology Publications.

Merrill, M.D. (1997, November-December). Instructional strategies that teach. CBT Solutions, pp. $1-11$.

Michell, L. (2001, April). E-Learning methods offer a personalized approach. Info World, pp. 174-185.

Muzio, J.A., Heins, T., \& Mundell, R. (2002). Experiences with reusable e-learning objects. Internet and Higher Education, 5, 21-34.

Palloff, R., \& Pratt, K. (1999). Building learning communities in cyberspace: Effective strategies for online classroom. San Francisco: Jossey-Bass.

Palloff, R., \& Pratt, K. (2003). The virtual student: A profile and guide to working with online learners. San Francisco: Jossey-Bass.

Pazos, J., Azpiazu, J., Silva, A., \& Rodríguez-Patón, A. (2002). A virtual classroom based on academic memories. In Proceedings of Information Society and Education: Monitoring a Revolution Badajoz, Spain: Government of Extremadura (pp. 87-92).

Sampson, D. (2002). An architecture for web-based e-learning promoting re-usable adaptive educational e-content. Educational Technology and Society Journal, 5(4), 27-37.

Schonotz, W., \& Bannert, M. (2003). Construction and interference in learning from multiple representations. Learning and Instruction, 13(2), 141-156.

Schulman, L.S. (2002). Making differences: A table of learning. Change, 34, 36-44.

Stahl, G. (2005). Group cognition in computer-assisted collaborative learning. Journal of Computer Assisted Learning, 2, 79-90.

Tallent-Runnels, M.K., Lan, W.Y., Fryer, W., Thomas, J.A., Cooper, S., \& Wang, K. (2005). The relationship between problems with technology and graduate students' evaluations of online teaching. Internet and Higher Education, 8, 167-174.

Tam, M. (2000). Constructivism, instructional design and technology: Implications for transforming distance learning. Educational Technology and Society, 2, 124-138.

Thorne, K. (2003). Blended learning: How to integrate online and traditional learning. London: VA Kogan. 